RESENHA

\title{
\#Ni una menos desde los primeros años: educación en géneros para infancias más libres
}

\author{
Luciana Cristina Porfírio
}

(1D

FINK, N.; MERCHÁN, C. (comps.). \#Ni una a menos desde los primeros años: educación en géneros para infancias más libres. 1. ed. Buenos Aires: Las Juanas Editoras; Chirimbote, 2016. 208 p.

O movimento feminista Ni una a menos, deflagrado na Argentina em 2015 em virtude do aumento considerável de crimes de feminicídio no país, difundido também por países sul-americanos como Bolívia, Chile, Colômbia, Equador, Paraguai, Uruguai, Venezuela, além de países europeus como Espanha e Itália, buscou desinvisibilizar as múltiplas identidades de gênero para deter a violência em suas variadas faces. O livro organizado por Cecilia Merchán e Nadia Fink, publicado pelas editoras argentinas Las Juanas e Chirimbote em novembro de 2016, é resultante de parte das pautas que foram ali levantadas. Contendo introdução e dez capítulos, a obra reúne reflexões e análises sobre diversidade e igualdade de gênero para a construção de relações sociais que rompam com a naturalização da violência histórica e cíclica das sociedades estruturadas sob a égide da dominação masculina. Publicada na Espanha pela editora Maime Mujer, ainda não chegou ao Brasil nem foi traduzida para a língua portuguesa.

Nesse livro, a educação em gêneros caracteriza-se pela proposta de ruptura com as estruturas sociais patriarcais e seus mandatos de gênero mediante a democratização e a socialização de conhecimentos visando à construção de uma epistemologia feminista que esteja integrada à formação dos indivíduos desde o seu nascimento, porque, apesar dos avanços já conquistados, estes são insuficientes para promover a necessária mudança de paradigmas. Para que isso deixe de ser uma utopia, a escola e seus professores, como agentes de transformação responsáveis pela transmissão de conteúdos curriculares e desenvolvimento de subjetividades, também são produtores de cultura e, do mesmo modo, estereótipos a ela agregados.

O diálogo e a difusão de conhecimentos em gênero são uma forma de combater a violência, e a sua omissão pode agravar tais ocorrências. Em \#Ni una a

'Universidade Federal de Goiás, Jataí, GO, Brasil. 
menos, pela linguagem (referencial), antropólogos, ativistas LGBTTTI (Lésbico, gay, bissexual, transexual, transgênero, travesti e intersexual), uma escritora literária, uma deputada, uma jornalista, professores, psicólogos e sociólogos trazem elementos que permitem a compreensão histórica de como, oficial e cotidianamente, diferenças sexuais biológicas foram e vêm sendo usadas para a construção de estereótipos, de preconceitos e discriminações, de injustiças e desigualdades de gênero.

Os antropólogos Mónica Tarducci e Marcelo Zelarallán iniciam o primeiro capítulo, "Nuevas historias: géneros, convenciones e instituciones", analisando como as instituições tradicionais - matrimônio, família nuclear, sindicatos, igrejas, escolas, mídia, entre outras - produzem modelos hegemônicos de masculinidade e de feminilidade que se expressam nas relações de inferiorização, desigualdade e exclusão social das mulheres. Retomam o contexto histórico do movimento feminista e as relações construídas com base em um modelo heteronormativo que transforma diferenças de ordem biológicas em desigualdade por meio da inculcação de arquétipos e convenções, aprovações prescrições e proibições que vão moldando os comportamentos esperados de meninos e meninas.

Em “Toda educación es sexual”, a socióloga Graciela Morgade reafirma que as instituições família e escola são responsáveis pela transmissão de significados hegemônicos sobre o que é e como deve ser a mulher ou o homem como se fossem naturais, que se enraízam nas diferentes culturas gerando discriminação de gênero contra todos aqueles sujeitos que não respondam às definições dadas. Essa construção se inicia com o nascimento e segue ao longo da vida no campo educativo pelo currículo formal, oculto e em ação, que reforça preconceitos discriminatórios celebrando somente heróis, militares ou políticos homens, ou quando o(a) professor(a) usa linguagens distintas para meninas e meninos projetando expectativas de desempenhos e comportamentos esperados. $\mathrm{O}$ currículo omitido vigora quando os temas são silenciados ou proibidos, como a sexualidade, superficialmente abordada por suas características biológicas e heterossexuais.

O terceiro capítulo, "De brujas y princesas: la literatura y el cine en la producción de estereotipos de género", da escritora Nadia Fink, reflete os estereótipos de gênero nos livros infantis e nos desenhos animados do cinema, em especial nas narrativas Disney, que, embora apresentem adaptações trazendo princesas mais ativas em filmes como Valente ou Enrolados, ainda mantêm os velhos paradigmas que perpetuam a ordem social patriarcal. São adolescentes de traços perfeitos e corpo magro materializados em bonecas do tipo "Barbie", produzidas pela indústria cultural e vendidas para as meninas. Trazem representações simbólicas e estereotipadas sobre as mulheres serem rivais, invejosas, que esperam ser salvas pelos homens (provedores, cúmplices ou salvadores), que aceitam seus destinos passivamente — serem princesas ou rainhas, bondosas, tolerantes, mães perfeitas, mantendo o legado familiar para o regozijo da sociedade estruturada pela dominação masculina. As bruxas, velhas e disformes, estigmatizadas como promotoras das pragas e maldições; e a madrasta, a futura companheira do pai, apresentada como pessoa má e perversa, que usa a inteligência para prejudicar os outros, mostrando qual é o lugar social das mulheres que ousam desafiar a ordem social existente. 
"Prácticas culturales y géneros: el juego y el juguete como estrategias cotidianas para la equidad", escrito pela socióloga Marcela Alejandra País Andrade, é o título do quarto capítulo. Nele, os jogos e os brinquedos são apontados como importantes elementos constituintes da educação das crianças, mas também como um modo de controle social capaz de desvendar as construções sociais que giram em torno desses instrumentos. Tais construções ocorrem por simbologias e sentidos que se expressam na compra para as meninas de bonecas, minicozinhas, ferro de passar roupas, panelinhas, entre outras peças características de ambientes domésticos, e bolas, carros e ferramentas, que denotam ambientes públicos e fora do lar, para os meninos.

No quinto capítulo, "Acerca de la construcción de la identidad de género", as psicólogas Josefina Isnardi e Mariana Torres Cárdenas não concebem sexo e gênero como sinônimos, mas analisam como nas sociedades patriarcais a identidade de gênero é construída pela leitura dos órgãos genitais e da anatomia e que o sexo da mulher e do homem se manifestará no desenvolvimento de uma identidade feminina e masculina, como se esse binarismo heterossexual que afeta ambos os sexos fosse algo natural. Para as psicólogas, múltiplos sentidos se vão refletindo em práticas discursivas que cristalizam saberes associando as mulheres ao instinto maternal, como seres sensíveis, submissas, entre outras, e o inverso para os homens, tais como homens não choram, são fortes, análise que não simplifica a questão de gênero somente aos estudos de mulheres.

O sexto, sétimo e oitavo capítulos trazem histórias de vida durante a infância de Susana Pita, ativista LGBTTI e membro do coletivo Córdoba, autora de "Los prejuicios lastiman"; de Alan Otto Prieto, ativista trans e membro do movimento Capicüa, com "Infancias trans"; e Carolina Unrein, secundarista e ativista do coletivo Diamante, com "Si tuviera un deseo, sería revisar mis privilegios", que testemunham as discriminações vividas por não se encaixarem no estereótipo hétero estabelecido pela dominação masculina.

As antropólogas Virginia Negrete e María de las Mercedes e a professora de educação de jovens e adultos (EJA) Irene de Isla no nono capítulo, "Historiando el concepto de infancia", realizam uma incursão histórica sobre a construção da infância ao longo dos séculos, detendo-se no fenômeno que se originou com o advento da modernidade na Europa no século XVII, conhecido na Argentina como "Particularización de la Infancia". A conformação dos Estados-nação europeus e as novas relações econômicas e sociais construíram a ideia de infância concomitante ao nascimento e à disseminação de um modelo nuclear de família que privilegiava a educação masculina em detrimento da feminina, ocorrendo de formas distintas para os setores menos abastados, forjando a família e a infância popular como objetos políticos, sociais e culturais integrados aos processos hegemônicos mais amplos.

"Ni una menos desde los primeros años", da jornalista Cecilia Merchán, é o título do décimo capítulo, que justifica toda educação desde o nascimento pautada pela igualdade, justiça e solidariedade, para que todas as pessoas cresçam livres meninos e meninas -, sem fome, ao abrigo de um teto, com emprego para os adultos que delas cuidam e escolas que não negligenciem ou omitam problemas sociais, promovendo inúmeras discriminações, já que toda injustiça precisa ser combatida. 
Para finalizar, a importância dessa leitura consiste em revelar o sexismo enraizado nas sociedades pelas "relações de poder" inculcadas em mentes e corpos, predeterminando o que é ser mulher ou ser homem. Apesar disso, corpos e mentes resistem, rebelam-se e revelam-se, transgredindo os padrões estabelecidos não sem as marcas de sofrimentos ou dores, como nos relatos das "infâncias" dos ativistas, em virtude do modelo educacional binário que em qualquer espaço institucional oprime e silencia identidades, segrega e discrimina pessoas. Já para a sociedade brasileira e seu nível ascendente de violência contra as mulheres e feminicídio, então motivados pela condição de gênero, a obra é um alerta para intervir na gênese dessa "asfixia social" que não pode mais ser silenciada e negligenciada, o que exige uma reconfiguração epistemológica da educação infantil, tendo a igualdade como ponto de partida e de chegada na escola e nas demais instituições com as quais ela dialoga.

\section{REFERÊNCIAS}

FINK, N.; MERCHÁN, C. (comps.). \#Ni una a menos desde los primeros años: educación en géneros para infancias más libres. 1. ed. Buenos Aires: Las Juanas Editoras; Chirimbote, 2016. 208 p.

\section{SOBRE A AUTORA}

Luciana Cristina Porfírio é doutora em educação pela Universidade de São Paulo (USP). Professora da Universidade Federal de Goiás (UFG). E-mail: luciana_cristina@ufg.br

Recebido em 6 de fevereiro de 2020 Aprovado em 24 de abril de 2020 